\title{
Isoenzimatic Analysis of Four Anopheles (Kerteszia) cruzii (Diptera: Culicidae) Populations of Brazil
}

\section{Carlos José de Carvalho-Pinto/ ${ }^{+}$, Ricardo Lourenço-de-O liveira*}

\begin{abstract}
Departamento de Microbiologia e Parasitologia, CCB, Universidade Federal de Santa Catarina, 88040-900 Florianópolis, SC, Brasil *Departamento de Entomologia, Instituto Oswaldo Cruz-Fiocruz, Rio de Janeiro, RJ, Brasil
\end{abstract}

Anopheles cruzii is a small sylvatic mosquito and primary human Plasmodium vector in Southern Brazil. The distribution of this bromeliad-breeding mosquito follows the Atlantic forest coastal distribution, where bromeliads are abundant. Morphological, genetic, and molecular polymorphisms among different populations have been reported and it has recently been suggested that An. cruzii is a complex of cryptic species. The aim of this work is to analyze the gene flow between different populations of An. cruzii collected in four localities within the geographic distribution range of the species, and to examine if An. cruzii is a complex of cryptic species. The genetic distances show that populations of the states of Santa Catarina, São Paulo, and Rio de Janeiro are genetically closer (0.032 to 0.083) than populations of Bahia (0.364 to 0.853) based on profiles from 10 distinct isoenzyme loci. The $F_{\text {st }}$ was lower (0.077) when the Bahia population was excluded than when it was included (0.300) in the analyses. The inferred number of migrants per generation was 2.99 individuals among populations from the states of Santa Catarina, São Paulo, and Rio de Janeiro and 0.58 migrants per generation among all populations. Results suggest that An. cruzii is a complex of species and that the specimes of state of Bahia can be considered as belonging to a species that is distinct from other three closely-related populations studied.

Key words: isoenzyme - Anopheles cruzii - Kerteszia - cryptic species

Malaria vectors in Brazil belong to the Nyssorhynchus and Kerteszia subgenus of genus Anopheles (Deane 1986, Consoli \& Lourenço de Oliveira 1994). Members of Kerteszia are typically small tropical mosquitoes distributed from Southern Mexico to Southern Brazil where immatures develop within bromeliads.

Anopheles (Kerteszia) cruzii Dyar and Knab is a primary vector of human Plasmodium which is endemic in Southern and Southeastern Brazil (Rachou 1958, Aragão 1964). Currently An. cruzii is involved in the maintenance of several species of human and simian malaria that occurs in the valleys of the Atlantic Coastal Rain Forest in both states Rio de Janeiro and São Paulo (Carvalho et al. 1988, Azevedo 1997, Branquinho et al. 1997). In addition, this species is a vector of the simian malarias in Brazil (Deane 1986).

Morphological differences were observed among populations of An. cruzii from Rio de Janeiro and Santa Catarina (Zavortink 1973). Ramirez and Dessen (1994) and Ramirez et al. (1994) described a high genetic polymorphism based on polytene chromosome banding pattern of An. cruzii from southern state of São Paulo. In comparison to other species of the same subgenus, the authors relate this phenomenon to the plasticity in selection of breeding places, especially in terms of the size and shade.

${ }^{+}$Corresponding author. Fax: +55-48-331.9512. E-mail: ccb1ccp@ccb.ufsc.br

Received 19 November 2003

Accepted 16 June 2004
Malafronte et al. (1997) observed a high polymorphism in restriction profiles of the ribosomal DNA (ITS2) among An. cruzii populations collected in five distinct areas of state of São Paulo.

Ramirez and Dessen (2000a), studying the polytene chromosomal banding pattern of An. cruzii from São Paulo and Santa Catarina, observed the existence of two distinct chromosomic forms and the absence of heterozygotes, which can indicate that An. cruzii is a complex of cryptic species. Ramirez and Dessen (2000b) found a third chromosomic form in two areas of São Paulo and concluded that the proposed complex was formed by at least three cryptic species.

The aim of this work is to analyze the gene flow between different populations of An. cruzii collected in four localities within the geographic distribution range of the species, and to examine if An. cruzii is a complex of cryptic species.

\section{MATERIALSAND METHODS}

Mosquito sampling - All mosquitoes included in this study were captured at forest borders of the states of Santa Catarina, São Paulo, Rio de Janeiro, and Bahia (Fig. 1).

All captured females were killed by freezing, morphologically identified using the Consoli and Lourenço de Oliveira's key (1994) and then stored in liquid nitrogen for isoenzymatic analysis.

Isoenzyme electrophoresis was performed on agarose gels as described by Hjèten (1961) using modifications proposed by Salles et al. (1986). Briefly, females were individually processed in $40 \mu \mathrm{l}$ lysis buffer $(0.05 \mathrm{mM}$ Tris- $\mathrm{Hcl}$ $\mathrm{pH}=8.0,0.01 \mathrm{mM}$ EDTA, $0.01 \mathrm{mM} \varepsilon$-amino n-caproic acid and $1 \%$ Triton-100X) in 96 well plates in an ice bath.

Sixteen enzyme systems were analyzed by agarose gel 


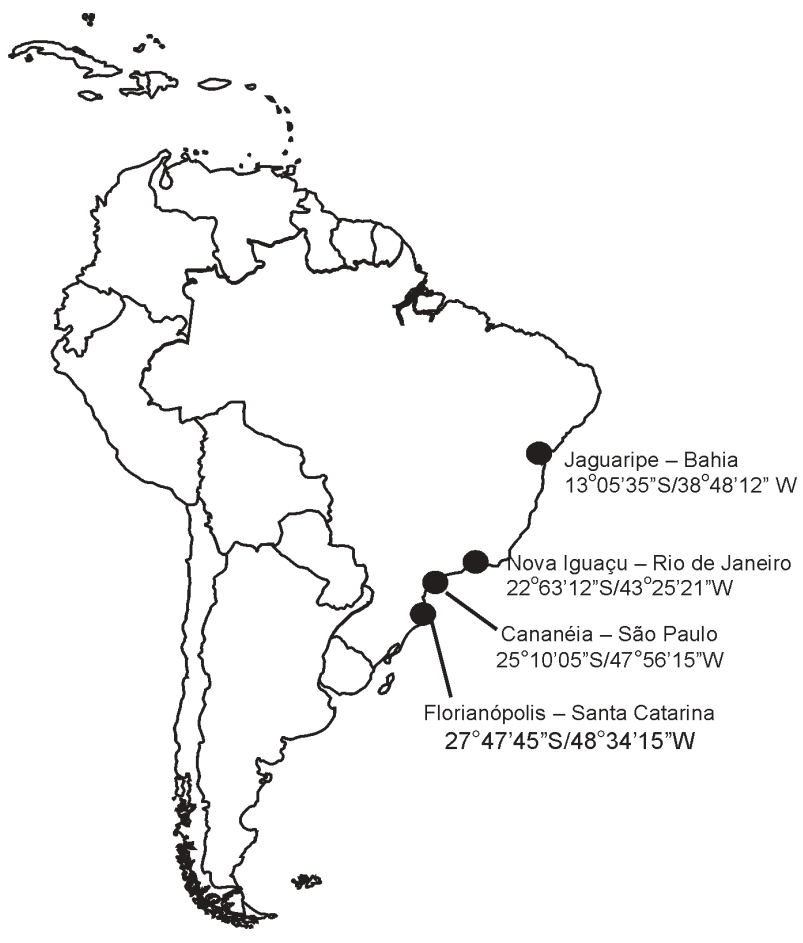

Fig. 1: source of specimens of Anopheles cruzii used in isoenzyme analyses.

electrophoresis using $2 \mu \mathrm{l}$ of the lysate for approximately $2 \mathrm{~h}$ at $4^{\circ} \mathrm{C}$ in appropriate buffers. Detection of each enzyme was carried out by overlaying the electrophoresis gel with a solution of $10 \%$ agarose supplemented with specific substrates, co-enzymes and co-factors (for more details see Rosa-Freitas et al. 1992). After development in darkness for 20-60 min at room temperature, the enzymatic reactions were stopped by adding of $5 \%$ acetic acid. The gels were dried at room temperature and the analysis genotypic frequencies performed using the BYOSIS software (Swofford \& Selander 1981).

\section{RESULTS}

Among the of 16 enzymatic systems tested, 10 revealed clear banding patterns [phosfoglucomutase - EC 5.4.2.2 (PGM), hexokinase-E.C. 2.7.1.1 (HK), fumarate hydratase EC 4.2.1.2 (FUM), malic enzyme EC 1.1.1.40(ME), malate dehydrogenase - E.C. 1.1.1.37 (MDH, glucose-6-phosphate isomerase- EC 5.3.1.9 (GPI), Isocitrate dehydrogenase - EC 1.1.1.42 (IDH), leucyl aminopeptidase - EC 3.4.11.1 (PEP-1), tripeptide aminopeptidase - EC 3.4.11.4 (PEP-2), membrane alanyl aminopeptidase - EC 3.4.11.2 (PEP-3)], with ME showing two distinct loci. Allelic frequencies of all An. cruzii loci analyzed are listed in Table I. A monomorphic pattern was observed for HK and FUM enzymes in all samples, whereas GPI and PEP-3 were monomorphic for Bahia and Santa Catarina populations, respectively (Table I).

The mean number of alleles per locus ranged from 2.5 to 3.0 , and the percentage of polymorphic loci ranged from $72.7 \%$ for the Santa Catarina and Bahia populations to $81.8 \%$ for the São Paulo and Rio de Janeiro populations.
The mean heterozygosity among the studied samples ranged from 0.211 to 0.386 (Table II).

The genetic distance estimed according to Nei (1978) shows that populations from the states of Santa Catarina, São Paulo, and Rio de Janeiro are genetically closer to each other ( 0.032 to 0.083$)$ than to the population from Bahia (0.364 to 0.853). Genetic identities varied from 0.921 to 0.968 among populations of the states of Santa Catarina, São Paulo, and Rio de Janeiro and from 0.426 to 0.530 between these populations and the samples from Bahia (Table III, Fig. 2).

Considering that the Bahia population exhibited a higher genetic distance from other three populations analyzed, the F-statistics (Fst), was estimated the population from Bahia both included and excluded. As a result, when the population from Bahia was excluded from analysis, the $\mathrm{F}_{\mathrm{st}}$ was lower (0.077) than when it was included (0.300) (Table IV). The inferred migrants per generation were 2.99 individuals among populations of the states of Santa Catarina, São Paulo, and Rio de Janeiro and 0.58 migrants per generation among all populations.

\section{DISCUSSION}

Zavortink (1973) suggested that An. cruzii could represent more than a single species. After a long gap lasting up until only a few years ago, Ramirez and Dessen (2000a), studying the polytene chromosomes banding pattern of distinct populations of An. cruzii from Brazil, showed that the population studied have high genetic diversity and thus An. cruzii may represent a complex of cryptic species. The results of the present analysis are in agreement with both Zavortink (1973) and Ramirez and Dessen (2000a) hypotheses. Additionally, the present results also show that the population of An. cruzii from Bahia has a distinct isoenzymatic profile in comparison to the profiles of the other populations included in this study.

As shown in Table III, An. cruzii samples from Southern and Southeastern Brazil (Santa Catarina, São Paulo, and Rio de Janeiro) show genetic distances and identities, which vary from 0.032 to 0.083 and from 0.921 to 0.968 , respectively. Nevertheless, the Bahia population is shown to be quite distant from the others, showing values for genetic distance and identity of 0.364 to 0.853 and from 0.426 to 0.530 , respectively. In conclusion, isoenzyme analysis revealed that An. cruzii populations of Santa Catarina, São Paulo, and Rio de Janeiro are closely related to each other and are genetically distinct from population of the Bahia.

According to Bullini (1982), genetic distance values greater than 0.2 are observed in individuals belonging to cryptic species complexes of mosquitoes. The critical value for genetic distance in order to distinguish between species is 0.35 (Thorpe \& Solé-Cava 1994). Considering these values, our results suggests that (i) An. cruzii is a complex of species, (ii) specimens of the Bahia may be a distinct species, which is not An. cruzii, and (iii) An. cruzii populations of Santa Catarina, São Paulo, and Rio de Janeiro are closely related.

Excluding population of Bahia from the analysis, the results of $\mathrm{F}$ statistics, i. e. $\mathrm{F}_{\text {is }}$ and $\mathrm{F}_{\text {it, }}$ did not show significative alterations. However, the $\mathrm{F}_{\mathrm{st}}$ value, which indicates 
TABLE I

Allelic frequencies of Anopheles cruzii populations Santa Catarina (SC), São Paulo (SP), Rio de Janeiro (RJ), Bahia (BA)

\begin{tabular}{|c|c|c|c|c|}
\hline \multirow[b]{2}{*}{ Locus } & \multicolumn{4}{|c|}{ Populations } \\
\hline & $\mathrm{SC}$ & SP & RJ & BA \\
\hline \multicolumn{5}{|l|}{ PGM } \\
\hline $\mathrm{n}$ & 30 & 30 & 30 & 30 \\
\hline A & 0.033 & 0.000 & 0.017 & 0.000 \\
\hline B & 0.033 & 0.000 & 0.000 & 0.000 \\
\hline $\mathrm{C}$ & 0.833 & 0.583 & 0.600 & 0.000 \\
\hline $\mathrm{D}$ & 0.100 & 0.317 & 0.300 & 0.017 \\
\hline $\mathrm{E}$ & 0.000 & 0.100 & 0.083 & 0.000 \\
\hline $\mathrm{F}$ & 0.000 & 0.000 & 0.000 & 0.917 \\
\hline $\mathrm{G}$ & 0.000 & 0.000 & 0.000 & 0.067 \\
\hline \multicolumn{5}{|l|}{$\mathrm{HK}$} \\
\hline $\mathrm{n}$ & 30 & 30 & 30 & 30 \\
\hline A & 1.000 & 1.000 & 1.000 & 1.000 \\
\hline \multicolumn{5}{|l|}{ FUM } \\
\hline $\mathrm{n}$ & 30 & 30 & 30 & 30 \\
\hline A & 1.000 & 1.000 & 1.000 & 1.000 \\
\hline \multicolumn{5}{|c|}{ ME-1 } \\
\hline $\mathrm{n}$ & 30 & 30 & 31 & 30 \\
\hline $\mathrm{A}$ & 0.017 & 0.000 & 0.032 & 0.667 \\
\hline B & 0.017 & 0.083 & 0.339 & 0.333 \\
\hline $\mathrm{C}$ & 0.967 & 0.917 & 0.629 & 0.000 \\
\hline \multicolumn{5}{|c|}{ ME-2 } \\
\hline $\mathrm{n}$ & 30 & 30 & 30 & 30 \\
\hline A & 0.900 & 0.467 & 0.550 & 0.000 \\
\hline B & 0.100 & 0.300 & 0.450 & 0.000 \\
\hline $\mathrm{C}$ & 0.000 & 0.233 & 0.000 & 0.100 \\
\hline D & 0.000 & 0.000 & 0.000 & 0.900 \\
\hline \multicolumn{5}{|c|}{$\mathrm{MDH}$} \\
\hline $\mathrm{n}$ & 30 & 30 & 30 & 30 \\
\hline A & 0.000 & 0.167 & 0.083 & 0.000 \\
\hline B & 0.600 & 0.350 & 0.450 & 0.133 \\
\hline $\mathrm{C}$ & 0.217 & 0.383 & 0.333 & 0.700 \\
\hline $\mathrm{D}$ & 0.183 & 0.100 & 0.133 & 0.167 \\
\hline \multicolumn{5}{|l|}{ GPI } \\
\hline $\mathrm{n}$ & 30 & 24 & 26 & 30 \\
\hline A & 0.067 & 0.146 & 0.058 & 1.000 \\
\hline B & 0.917 & 0.708 & 0.846 & 0.000 \\
\hline $\mathrm{C}$ & 0.017 & 0.146 & 0.096 & 0.000 \\
\hline \multicolumn{5}{|l|}{ IDH } \\
\hline $\mathrm{n}$ & 30 & 30 & 30 & 30 \\
\hline A & 0.000 & 0.000 & 0.167 & 0.933 \\
\hline B & 0.033 & 0.283 & 0.283 & 0.067 \\
\hline $\mathrm{C}$ & 0.917 & 0.667 & 0.550 & 0.000 \\
\hline D & 0.050 & 0.050 & 0.000 & 0.000 \\
\hline \multicolumn{5}{|c|}{ PEP-1 } \\
\hline $\mathrm{n}$ & 29 & 32 & 31 & 29 \\
\hline A & 0.0534 & 0.359 & 0.597 & 0.328 \\
\hline B & 0.190 & 0.156 & 0.000 & 0.362 \\
\hline $\mathrm{C}$ & 0.207 & 0.266 & 0.161 & 0.034 \\
\hline D & 0.069 & 0.188 & 0.210 & 0.086 \\
\hline E & 0.000 & 0.031 & 0.032 & 0.190 \\
\hline \multicolumn{5}{|c|}{ PEP-2 } \\
\hline $\mathrm{n}$ & 30 & 30 & 31 & 32 \\
\hline A & 0.517 & 0.217 & 0.000 & 0.250 \\
\hline B & 0.350 & 0.483 & 0.419 & 0.047 \\
\hline $\mathrm{C}$ & 0.117 & 0.283 & 0.290 & 0.188 \\
\hline $\mathrm{D}$ & 0.017 & 0.017 & 0.290 & 0.469 \\
\hline E & 0.000 & 0.000 & 0.000 & 0.047 \\
\hline \multicolumn{5}{|c|}{ PEP-3 } \\
\hline $\mathrm{n}$ & 30 & 30 & 30 & 30 \\
\hline A & 0.000 & 0.033 & 0.000 & 0.000 \\
\hline B & 0.000 & 0.050 & 0.000 & 0.000 \\
\hline C & 1.000 & 0.717 & 0.750 & 0.633 \\
\hline $\mathrm{D}$ & 0.000 & 0.200 & 0.250 & 0.367 \\
\hline
\end{tabular}

$\mathrm{n}$ : individuals 
TABLE II

Means and standard errors of samples per locus and alleles per locus, percentage of polymorphic locus, and mean heterozygozity and standard errors for four Anopheles cruzii populations from Santa Catarina (SC), São Paulo (SP), Rio de Janeiro (RJ),

Bahia (BA)

\begin{tabular}{lccccc}
\hline Population & $\begin{array}{c}\text { Mean sample } \\
\text { size/locus }\end{array}$ & $\begin{array}{c}\text { Mean number of } \\
\text { alleles/locus }\end{array}$ & \multicolumn{2}{c}{$\begin{array}{c}\text { Percentage of } \\
\text { polymorphic locus }\end{array}$} & \multicolumn{2}{c}{ Mean heterozygosity } \\
\cline { 5 - 6 } SC & $29.9 \pm 0.1$ & $2.6 \pm 0.4$ & 72.7 & $0.211 \pm 0.062$ & $0.244 \pm 0.076$ \\
SP & $29.6 \pm 0.6$ & $3.0 \pm 0.4$ & 81.8 & $0.353 \pm 0.067$ & $0.442 \pm 0.082$ \\
RJ & $29.9 \pm 0.4$ & $2.7 \pm 0.3$ & 81.8 & $0.386 \pm 0.070$ & $0.430 \pm 0.73$ \\
BA & $30.1 \pm 0.2$ & $2.5 \pm 0.4$ & 72.7 & $0.251 \pm 0.068$ & $0.298 \pm 0.083$ \\
\hline
\end{tabular}

Ho: observed heterozygosity; He: expected heterozygosity

TABLE III

Matrix of genetic identities (above diagonal) and distances (below diagonal) (Nei 1978) among four Anopheles cruzii populations

\begin{tabular}{lcccc}
\hline Population & SC & SP & RJ & BA \\
\hline SC & - & 0.948 & 0.921 & 0.426 \\
SP & 0.053 & - & 0.968 & 0.498 \\
RJ & 0.083 & 0.032 & - & 0.530 \\
BA & 0.853 & 0.698 & 0.364 & - \\
\hline
\end{tabular}

SC: Santa Catarina; SP: São Paulo; RJ: Rio de Janeiro; BA: Bahia

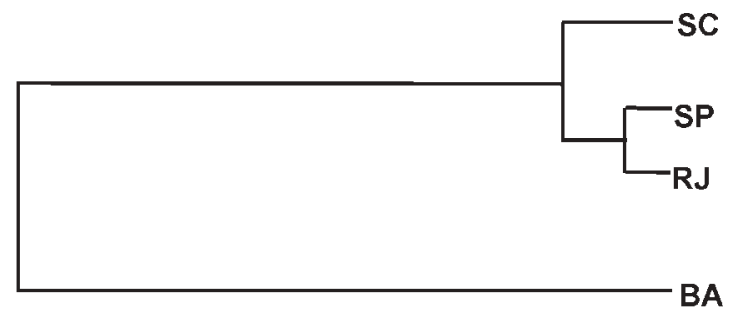

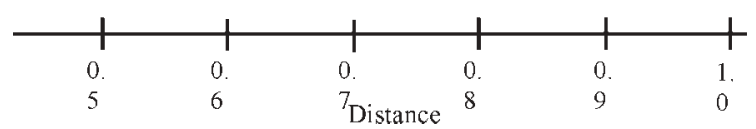

Fig. 2: cladogram of genetic distances between Anopheles cruzii populations. SC: Santa Catarina; SP: São Paulo; RJ: Rio de Janeiro; BA: Bahia

\section{TABLE IV}

Wright fixation indexes $\left(\mathrm{F}_{\mathrm{is}}, \mathrm{F}_{\mathrm{it}}\right.$, and $\left.\mathrm{F}_{\mathrm{st}}\right)$ for Anopheles cruzii populations with and without Bahia population

\begin{tabular}{lccc}
\hline Locus & $\mathrm{F}_{\text {is }}{ }^{a}$ & $\mathrm{~F}_{\text {it }}$ & $\mathrm{F}_{\text {st }}$ \\
\hline PGM & $0.199 / 0.230$ & $0.531 / 0.270$ & $0.414 / 0.051$ \\
ME-1 & $0.171 / 0.122$ & $0.555 / 0.253$ & $0.464 / 0.150$ \\
ME-2 & $0.129 / 0.162$ & $0.513 / 0.275$ & $0.441 / 0.134$ \\
MDH & $0.019 / 0.010$ & $0.118 / 0.022$ & $0.101 / 0.032$ \\
GPI & $0.153 / 0.153$ & $0.636 / 0.186$ & $0.570 / 0.039$ \\
IDH & $0.131 / 0.152$ & $0.523 / 0.235$ & $0.451 / 0.098$ \\
PEP-1 & $0.128 / 0.161$ & $0.184 / 0.190$ & $0.065 / 0.034$ \\
PEP-2 & $0.230 / 0.218$ & $0.337 / 0.297$ & $0.140 / 0.101$ \\
PEP-3 & $0.090 / 0.019$ & $0.184 / 0.077$ & $0.103 / 0.095$ \\
Média & $0.137 / 0.135$ & $0.396 / 0.201$ & $0.300 / 0.077$
\end{tabular}

$a$ : with Bahia population/without Bahia population the degree of genetic structure, was high (0.300) when the Bahia population was included in the analysis. On the other hand, when this population was excluded, the $\mathrm{F}_{\mathrm{st}}$ value was relatively low (0.077). When the Bahia population was not taken into consideration, the number of migrating individuals per generation (2.99) shows the occurrence of genetic flow among populations of Santa Catarina, São Paulo, and Rio de Janeiro, despite the current fragmentation of the Brazilian Atlantic Rain Forest. Including An. cruzii population from Bahia in the analyze, the $\mathrm{F}_{\mathrm{st}}$ value was high and almost no migrating individuals were observed, which indicates that there are no genetic exchanges between populations of An. cruzii from the Southern and Southeastern regions of Brazil and the Bahia population, located in the Northeastern region of the country. We did not find distinct isoenzymatic patterns in the samples from the states of São Paulo and Santa Catarina, which could be indicative of the presence of distinct populations of An. cruzii in the studied localities, as suggested by Ramirez and Dessen (2000a, b).

The results of the analysis are in agreement with and reinforce the hypothesis that An. cruzii is a complex of cryptic species, suggesting that the An. cruzii population of Bahia constitute an isolated population or distinct species.

We cannot infer if this new species is able to transmit malaria but, interestingly, An. cruzii never was considered a vector in Bahia. In the past, when malaria was endemic in the region, other anophelines of Nyssorynchus subgenus were considered responsible for transmission.

Studies are continued to verify if there are morphological differences between various isoenzymatic populations of An. cruzii.

\section{ACKNOWLEDGEMENTS}

To Dr Iná Kakitani, Catarina Macedo, and Pedro Martins for their help during mosquito capture in São Paulo, Rio de Janeiro, and Bahia, respectively. To Claudio Menezes for technical assistance in the laboratory and for discussions.

\section{REFERENCES}

Aragão MB 1964. Distribuição geográfica e abundância das espécies de Anopheles (Kerteszia) (Diptera, Culicidae). Rev Bras Malariol Doen Trop 16: 73-109.

Azevedo AL 1997. Aspectos da Epidemiologia da Malária e da Biologia de Anopheles (Kerteszia) cruzii Dyar \& Knab em Vales Montanhosos do Sistema de Mata Atlântica, MSc The- 
sis, Instituto Oswaldo Cruz, Rio de Janeiro, 94 pp.

Branquinho MS, Marreli MT, Curado I, Natal D, Barata JM, Tubaki R, Carreri-Bruno GC, de Menezes RT, Kloetzel JK 1997. Infecção de Anopheles (Kerteszia) cruzii por Plasmodium vivax e Plasmodium vivax variante VK247 nos municípios de São Vicente e Juquitibá, São Paulo. Rev Panam Salud Pública 2: 189-193.

Bullini L 1982 Enzyme variants in the identification of parasites and vectors: methodological aspects of eletrophoretic approach. In BN Newton, F Michal (eds), New Approaches to the Identification of Parasites and their Vectors, Tropical Research Series 5. UNDP/WHO, Geneva, Switzerland, p. 53-59.

Carvalho ME, Glasser CM, Ciaravolo RMC, Etzel A, Santos LA, Ferreira CS 1988. Sorologia de malária vivax no foco Aldeia do Índios, município de Peruíbe, Estado de São Paulo, 1984 a 1986. Cad Saúde Púb 4: 276-292.

Consoli RAGB, Lourenço-de-Oliveira R 1994. Principais Mosquitos de Importância Sanitária no Brasil, Fiocruz, Rio de Janeiro, 225 pp.

Deane LM 1986. Malaria vectors in Brazil. Mem Inst Oswaldo Cruz 81 (Suppl. II): 5-14.

Hjèrten S 1961. Agarose as a anticonventional agent in zone electrophoresis. Biochem Biophys Acta 52: 514-517.

Malafronte RS, Marreli MT, Carreri-Bruno GC, Urbinati PR, Marinoti O 1997. Polymorphism in the second internal transcribed spacer (ITS2) of Anopheles (Kerteszia) cruzii (Diptera: Culicidae) from state of São Paulo, Brazil. Mem Inst Oswaldo Cruz 92 (Suppl. I): 306.

Nei M 1978. Estimation of average heterozigosity and genetic distance from a small number of indiviuals. Genetics 89 : 583-590.
Rachou RG 1958. Anofelinos do Brasil: Comportamento das espécies vetoras de malária. Rev Bras Malariol Doen Trop 10: 145-181.

Ramirez CCL, Dessem EMB 1994. Cytogenetics analysis of a natural population of Anopheles cruzii. Rev Bras Genet 17: 41-46.

Ramirez CCL, Dessem EMB 2000a. Chromosomal evidence for sibling species of the malaria vector Anopheles cruzii. Genome 43: 143-151

Ramirez CCL, Dessem EMB 2000b. Chromosome differentiated populations of Anopheles cruzii: evidence for a third sibling species. Genetica 35: 1-8.

Ramirez CCL, Dessem EMB, Otto PA 1994. Inversion polymorphism in a natural population of Anopheles cruzii. Caryology 47: 121-130.

Rosa-Freitas MG, Broomfield G, Priestman A, Milligan PJ, Momen H, Molyneux DH 1992. Cuticular hydrocarbons, isoenzymes and behavior of three populations of Anopheles darlingi from Brazil. J Am Mosq Control Assoc 8: 357366

Salles CA, Silva AR, Momen H 1986. Enzyme typing and phenetic relationships in Vibrio cholerae. Rev Bras Genet 9: 407-419.

Swofford DL, Selander RB 1981. BIOSYS-1: a FORTRAN program for the comprehensive analysis of electrophoretic data in population genetics and systematics. $J$ Hered 72 : 281-283.

Thorpe JP, Solé-Cava AM 1994. The use of allozyme electrophoresis in invertebrate systematics. Zool Scr 23: 3-18.

Zavortink TJ 1973. Mosquito studies (Diptera: Culicidae). XXIX. A review of the subgenus Kerteszia of Anopheles. Cont Am Entomol Inst 9: 1-54. 
